\title{
Seasonal co-variability of surface downwelling longwave radiation for the 1982-2009 period in the Arctic
}

\author{
Mauro Boccolari ${ }^{1}$ and Flavio Parmiggiani ${ }^{2}$ \\ ${ }^{1}$ DSCG, University of Modena and Reggio Emilia, Modena, I41125, Italy \\ ${ }^{2}$ ISAC-CNR, Bologna, I40129, Italy \\ Correspondence to: Mauro Boccolari (mauro.boccolari@unimore.it)
}

Received: 11 January 2017 - Revised: 27 April 2017 - Accepted: 28 April 2017 - Published: 1 June 2017

\begin{abstract}
Trends and variability of the Arctic sea ice extent depend on various physical processes, including those related to changes in radiative fluxes, which are associated with cloudiness and water vapour and, in turn, with the atmospheric moisture transport over the Arctic. Aim of this work was: (i) to extract seasonal spatial patterns of the co-variability between the sea ice concentration (SIC) and the surface downwelling longwave radiation (SDL) in the Arctic Ocean during the 1982-2009 period; and (ii) to estimate the correlation coefficients between these patterns and the indices associated to some climate oscillation modes (AO, NAO, PNA, PDO and AMO). Maximum Covariance Analysis (MCA) was the main technique used in this study. Among our results, we highlight two areas of maximum co-variability SIC/SDL centered over the Barents Sea in winter and over the Chukchi Sea in summer. In addition, some statistically significant correlations (at $95 \%$ ) between the spatial patterns of co-variability and climate oscillation indices were assessed, e.g. with PDO and AMO in NovemberJanuary, with NAO and AMO in May-July, and with PNA in August-October.
\end{abstract}

\section{Introduction}

The drastic decrease of the Arctic sea ice, mainly due to the global warming (Vinnikov et al., 1999), is also modulated by several modes of variability. North Atlantic Oscillation (NAO) and Arctic Oscillation (AO) (Serreze et al., 2007), Atlantic Multi-decadal Oscillation (AMO) (Miles et al., 2014), Pacific Decadal Oscillation (PDO) (Screen and Francis, 2016), and Pacific North American pattern (PNA) (L'Heureux et al., 2008) all play a role in Arctic sea ice loss. These modes, associated with oceanic and atmospheric transports, act on the Arctic sea ice cover through different physical processes, for example, on the surface radiative fluxes (Kapsch et al., 2016). First, in this preliminary study, we investigated the correlation, for 28 years, between the surface downward longwave radiation (SDL) and the sea ice concentration (SIC) over the Arctic Ocean, in order to understand where the maximums of SDL/SIC seasonal co-variability are located. In addition, statistically significant correlations between the co-variability eigenvectors and the climatic oscillation indices of cited modes above (NAO, AO, AMO, PDO and PNA). All the results are re- lated to seasons defined as February-March-April (FMA), May-June-July (MJJ), August-September-October (ASO) and November-December-January (NDJ). Such seasonal grouping (e.g. Deser and Teng, 2008) was chosen because it represents a basic characteristic of the annual cycle in the Arctic where sea ice reaches its maximum extent around March and its minimum extent around September (Cavalieri and Parkinson, 2012).

\section{Data and methods}

Two main data sets, both referring to the 1982-2009 period, were used in this study. The first dataset is the Arctic monthly sea-ice concentration (SIC), distributed by the National Snow and Ice Data Center (NSIDC) (Cavalieri et al., 1996). SIC data are generated from brightness temperatures derived from SSMR, SSM/I and SSMIS observations. SIC data accuracy is generally $\pm 5 \%$ of the total during winter, and $\pm 15 \%$ during the Arctic summer melt and tends to be higher when sea ice is relatively thick $(>20 \mathrm{~cm})$ (Cavalieri et al., 1996). The spatial resolution, in a polar stereo- 


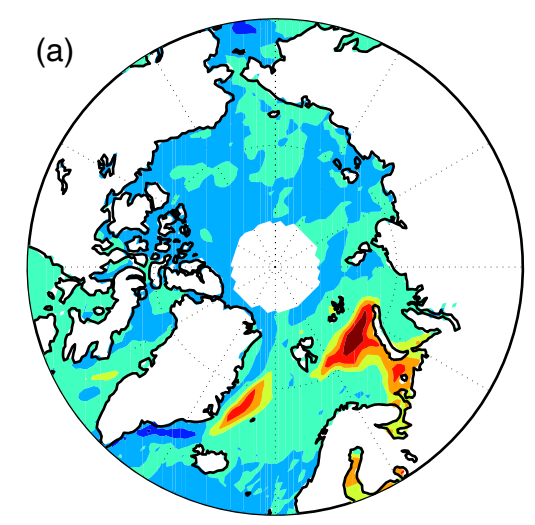

Figure 1. FMA (a) and ASO (b) spatial patterns (1st mode) of SIC.

graphic projection, is $25 \times 25 \mathrm{~km}^{2}$. The second dataset consists of the global monthly surface downward longwave radiation (SDL), which is a subset of the global area cover (GAC) climate data set CLARA-A1 (Karlsson et al., 2013) produced by the EUMETSAT's Satellite Application Facility on Climate Monitoring (CMSAF). All data were generated from satellite-derived measurements of AVHRR sensor on-board of NOAA and Metop polar-orbiting meteorological satellites. In particular, SDL data are derived by correcting the monthly-averaged downward longwave surface radiation from the ERA-Interim reanalysis with the CMSAF GAC cloud fraction (CFC) data set and with topographic information; in addition, a cloud correction factor (CCF) was taken into account for the impact of cloud coverage (Karlsson et al., 2012). The resolution is $0.25^{\circ}$ and the accuracy is $8 \mathrm{~W} \mathrm{~m}^{-2}$ (Karlsson et al., 2012). Not all global data were used in this study, but only those with latitude above $60^{\circ} \mathrm{N}$. In addition, as we are interested to the Arctic Ocean co-variability, using a land/mask computed by interpolating the equivalent NSIDC land/sea mask at $12^{\circ}$ resolution, only SDL sea cells were considered.

The Maximum Covariance Analysis (MCA), also known as Singular Value Decomposition (SVD) analysis, is a technique which finds pairs of linear combinations, $\mathbf{U}$ and $\mathbf{V}$, of two sets of vector data $\mathbf{X}$ and $\mathbf{Y}$ such that their covariances are maximized. That is, if $\left\{\begin{array}{l}\mathbf{U}=\mathbf{L}^{\mathbf{T}} \mathbf{X} \\ \mathbf{V}=\mathbf{R}^{\mathbf{T}} \mathbf{Y}\end{array}\right.$ then $\operatorname{cov}(\mathbf{U}, \mathbf{V})=$ $\mathbf{L}^{\mathbf{T}} \mathbf{S}_{\mathbf{X Y}} \mathbf{R}$ is maximized with the constraint that $\mathbf{L}$ and $\mathbf{R}$ vectors are orthonormal. The vectors $\mathbf{L}$ and $\mathbf{R}$ are obtained through a SVD of the cross-covariance matrix $\mathbf{S}_{\mathbf{X Y}}=\mathbf{L} \boldsymbol{\Omega} \mathbf{R}^{\mathbf{T}}$ where $\boldsymbol{\Omega}$ is the diagonal matrix of singular values of SVD. The method is usually applied in climatology to two combined data fields in order to identify pairs of coupled spatial patterns, with each pair expressing a fraction of the covariance between the two fields. The fraction of squared covariance (SCF) for $i$ th singular value $\omega_{i}$, is given by $\mathrm{SCF}_{i}=$ $\omega_{i} / \operatorname{trace}(\boldsymbol{\Omega})$ (Bjornsson and Venegas, 1997).

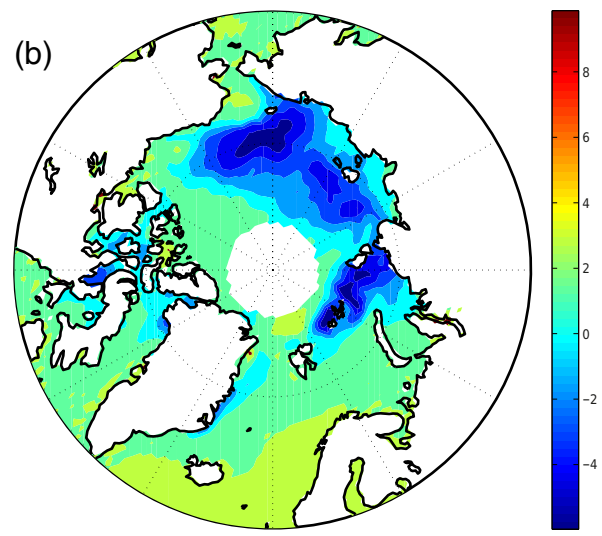

\section{Results}

MCA was applied to seasonal SIC and SDL fields after a proper sampling. A sampling is needed because, for each year, the original seasonal SDL (both sea and land) and SIC matrices are composed by 172800 and 136192 cells, respectively. The submission of such large matrices to the SVD algorithm would lead to computational problems. Therefore, the SDL and SIC matrices were reduced to $180 \times 120=$ 21600 and $136 \times 192=17024$ cells, respectively.

The computation of SCF shows that the first two modes of coupled patterns explain, for each season, the $38,35,48$ and $50 \%$ of the covariance, respectively. In Figs. 1 and 2, late winter/early spring (FMA) and late summer/early fall (ASO) spatial patterns of the first main mode of co-variability, of SDL and SIC, respectively, are shown. For winter (and also the NDJ season) one can observe an area with maximums of co-variability, both for SIC and SDL, located in the Barents Sea (Figs. 1a and 2a). In this region it was observed the largest decrease of Arctic sea ice during 1979-2006 (Parkinson and Cavalieri, 2008) and an increase of air temperature (Levitus et al., 2009). During the "Arctic summer" (ASO), SDL maximums are mainly found in the Chukchi Sea Fig. 2a), a region characterized by several circulation flows (Woodgate et al., 2005).

The second goal of this work was the search of significant correlation coefficients between the relevant modes of climate variability in the Arctic and the expansion coefficients supplied by the SVD analysis previously described. Table 1 gives the statistically significant (at $95 \%$ ) correlation coefficients (only those related to the first mode are shown). We can note that the correlation is statistically significant for both SDL and SIC, with the following climate oscillations:

- The AMO during NDJ and MJJ, and also for all seasons if the 2nd mode of co-variability was considered, In Levitus et al. (2009) the link with AMO was observed in the region of the Barents Sea. 

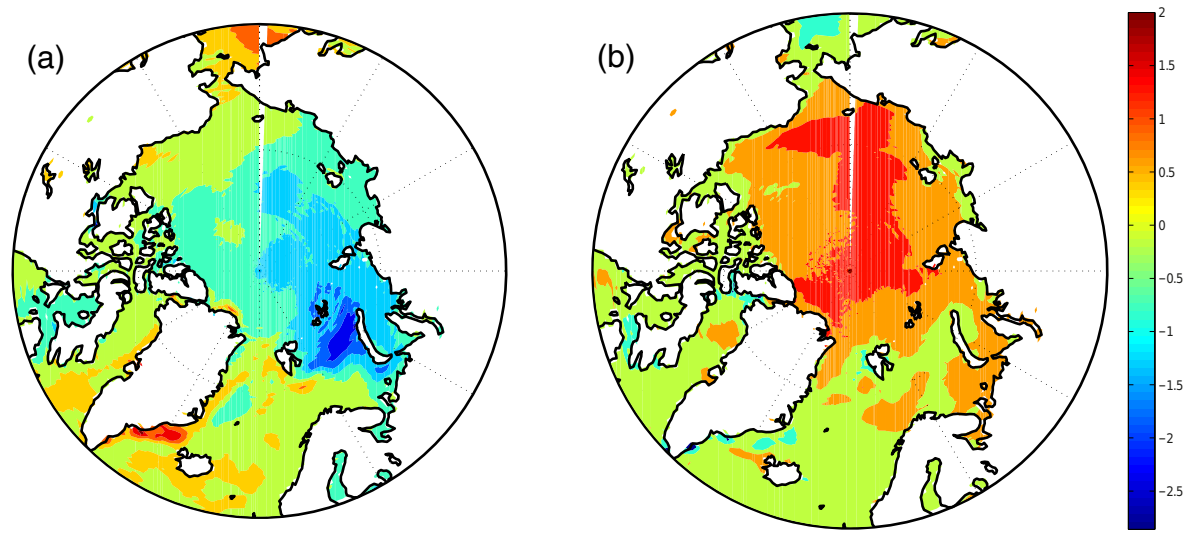

Figure 2. FMA (a) and ASO (b) spatial patterns (1st mode) of SDL.

Table 1. Oscillation indices (OI) having correlation statistically significant at $95 \%$ with seasonal SDL (left) and SIC (right) (only mode 1 is shown).

\begin{tabular}{llrr|llrr}
\hline & \multicolumn{2}{c}{ SDL } & \multicolumn{4}{c}{ SIC } \\
\hline Season & OI & Mode & Corr. & Season & OI & Mode & Corr. \\
\hline FMA & & & & FMA & PDO & 1 & 0.48 \\
\hline MJJ & NAO* & 1 & -0.39 & MJJ & NAO & 1 & -0.44 \\
& AMO & 1 & 0.48 & & AMO & 1 & 0.59 \\
\hline ASO & PNA & 1 & 0.54 & ASO & PDO & 1 & -0.39 \\
& & & & & PNA & 1 & 0.76 \\
& & & & & AMO & 1 & 0.57 \\
\hline NDJ & PDO & 1 & 0.41 & NDJ & PDO & 1 & 0.41 \\
& AMO & 1 & -0.63 & & AMO & 1 & -0.63 \\
\hline
\end{tabular}

* The correlation is not statistically significant at $95 \%$ using another method to calculate it (in particular, a resampling technique)

- The PDO in NDJ correlation was found, both for SDL and SIC, with PDO. A link of PDO with sea ice changes was observed in Screen and Francis (2016).

- PNA teleconnection appears strong during the melting season (ASO), both for SDL and SIC, as already identified by L'Heureux et al. (2008) in relation to the sea ice decrement during 2007. This correlation is consistent with the location of maximum of 1st mode of covariability, that is the Chukchi Sea.

- When considering the 2nd mode of co-variability, correlations with $\mathrm{NAO}$ and/or $\mathrm{AO}$ appear in all seasons, but in NDJ, and are generally out-of-phase with AMO.

\section{Conclusions}

This work has shown that, in the Arctic Ocean, large part of co-variability between SIC and SDL occurs in winter and summer over the Barents Sea and the Chukchi Sea, respectively; these areas are in correspondence of the Bering Sea
Pacific gateway and of one of the two Atlantic gateways (the other being the Fram Strait). The moisture transport through these gateways, with associated different levels of cloudiness and water vapor, certainly involves longwave radiative flow anomalies and the consequent radiation changes which produce an increase or a decrease of sea ice concentration. Our analysis also focused on the strong correlations of the SDL/SIC co-variability with various climate oscillations, both interannual, decadal and multi-decadal (keeping in mind that our record only lasts 28 years): NAO, AO, PNA, PDO and AMO. Finally, a limit of this study is that it lacks the analysis of the cross-co-variability of SDL and SIC for different seasons. 
Data availability. (1) CLARA-A1: CM SAF cLouds, Albedo and Radiation dataset from AVHRR data - Edition 1 - Monthly Means / Daily Means / Pentad Means / Monthly Histograms https://doi.org/10.5676/EUM_SAF_CM/CLARA_AVHRR/V001

(Karlsson et al., 2012)

(2) Latitude, longitude, land-sea mask of Arctic 25-km data: psn25lats_v3.dat, psn25lons_v3.dat, gsfc_25n.msk in ftp: //sidads.colorado.edu/pub/DATASETS/seaice/polar-stereo/tools/

(3) Sea Ice Concentrations from Nimbus-7 SMMR and DMSP SSM/I-SSMIS Passive Microwave Data, Version 1 https://doi.org/10.5067/8GQ8LZQVL0VL (Cavalieri et al., 1996)

(4) Monthly AMO unsmoothed data from the Kaplas SST v2: https://www.esrl.noaa.gov/psd/data/correlation/amon.sm.long.data (downloaded on July 2016)

(5) Monthly AO index data: http://www.cpc.ncep.noaa.gov/ products/precip/CWlink/daily_ao_index/monthly.ao.index.b50.

current.ascii.table

(6) Monthly PNA index data: http://www.cpc.ncep.noaa.gov/ products/precip/CWlink/pna/norm.pna.monthly.b5001.current. ascii.table

(7) Monthly NAO index data: http://www.cpc.ncep.noaa.gov/ products/precip/CWlink/pna/norm.nao.monthly.b5001.current. ascii.table

Competing interests. The authors declare that they have no conflict of interest.

Acknowledgements. The authors are grateful to: NSIDC for SIC data and land-sea mask; EUMETSAT for SDL product provided through the SAF CM; NWS's CPC (USA) for providing monthly AO, NAO and PNA indices; NOAA's ESRL (USA) for providing the monthly AMO index.

Edited by: R. R. Colucci

Reviewed by: two anonymous referees

\section{References}

Bjornsson, H. and Venegas, S. A.: A manual for EOF and SVD analyses of climate data, McGill University, CCGCR Report No. 97-1, Montréal, Québec, 52 pp., 1997.

Cavalieri, D. J. and Parkinson, C. L.: Arctic sea ice variability and trends, 1979-2010, The Cryosphere, 6, 881-889, https://doi.org/10.5194/tc-6-881-2012, 2012.

Cavalieri, D. J., Parkinson, D. C., Gloersen, P., and Zwally, H.: Sea Ice Concentrations from Nimbus-7 SMMR and DMSP SSM/ISSMIS Passive Microwave Data, Boulder, Colorado USA: NASA National Snow and Ice Data Center Distributed Active
Archive Center, https://doi.org/10.5067/8GQ8LZQVL0VL, updated yearly, 1996.

Cavalieri, D. J., Parkinson, C. L., Gloersen, P., and Zwally, H. J.: Sea Ice Concentrations from Nimbus-7 SMMR and DMSP SSM/I-SSMIS Passive Microwave Data, Version 1. [ftp://sidads.colorado.edu/pub/DATASETS/nsidc0051_gsfc_ nasateam_seaice/final-gsfc/north/monthly/]. Boulder, Colorado USA. NASA National Snow and Ice Data Center Distributed Active Archive Center. https://doi.org/10.5067/8GQ8LZQVL0VL, 1996, updated yearly, [December 2014].

Deser, C. and Teng, A.: Recent Trends in Arctic Sea Ice and the Evolving Role of Atmospheric Circulation Forcing, 1979-2007, in: Arctic Sea Ice Decline: Observations, Mechanisms and Implications, edited by: DeWeaver, E. T., Bitz, C. M., and Tremblay, L.-B., American Geophysical Union, Washington, D.C., https://doi.org/10.1029/180GM03, 2008.

Kapsch, M.-L., Graversen, R. G., Tjernström, M., and Bintania, R.: The effect of downwelling longwave and shortwave radiation on Arctic summer sea ice, J. Climate, 29, 1143-1159, https://doi.org/10.1175/JCLI-D-15-0238.1, 2016.

Karlsson, K.-G., Riihelä, A., Müller, R., Meirink, J. F., Sedlar, J., Stengel, M., Lockhoff, M., Trentmann, J., Kaspar, F., Hollmann, R., and Wolters, E.: CLARA-A1: a cloud, albedo, and radiation dataset from $28 \mathrm{yr}$ of global AVHRR data, Atmos. Chem. Phys., 13, 5351-5367, https://doi.org/10.5194/acp-135351-2013, 2013.

Karlsson, K.-G., Riihelä, A., Müller, R., Meirink, J. F., Sedlar, J., Stengel, M., Lockhoff, M., Trentmann, J., Kaspar, F., Hollmann, R., and Wolters, E.: CLARA-A1: CM SAF cLouds, Albedo and Radiation dataset from AVHRR data - Edition 1 Monthly Means / Daily Means / Pentad Means / Monthly Histograms. Satellite Application Facility on Climate Monitoring, https://doi.org/10.5676/EUM_SAF_CM/CLARA_AVHRR/V001, 2012.

Levitus, S., Matishov, G., Seidovand, D., and Smolyar, I.: Barents Sea multidecadal variability, Geophys. Res. Lett., 36, L19604, https://doi.org/10.1029/2009GL039847, 2009.

L'Heureux, M. L., Kumar, A., Bell, G., Halpert, M. S., and Higgins, R. W.: Role of the Pacific-North American (PNA) pattern in the 2007 Arctic sea ice decline, Geophys. Res. Lett., 35, L20701, https://doi.org/10.1029/2008GL035205, 2008.

Miles, M. W., Divine, D. V., Furevik, T., Jansen, E., Moros, M., and Ogilvi, A. E. J.: A signal of persistent Atlantic multidecadal variability in Arctic sea ice, Geophys. Res. Lett., 41, 463-469, https://doi.org/10.1002/2013GL058084, 2014.

Parkinson, C. L. and Cavalieri, D. J.: Arctic sea ice variability and trends, 1979-2006, J. Geophys. Res., 113, C07003, https://doi.org/10.1029/2007JC004558, 2008.

Screen, J. A. and Francis, J. A.: Contribution of sea-ice loss to Arctic amplification is regulated by Pacific Ocean decadal variability, Nature Climate Change, 6, 856-860, https://doi.org/10.1038/nclimate3011, 2016.

Serreze, M. C., Holland, M. M., and Stroeve, J.: Perspectives on the Arctic's Shrinking Sea-Ice Cover, Science, 315, 1533-1536, 2007.

Vinnikov, K. Y., Robock, A., Stouffer, R. J., Walsh, J. E., Parkinson, C. L., Cavalieri, D. J., Mitchell, J. F. B., Garrett, D., and Zakharov, V. F.: Global Warming and Northern Hemisphere Sea Ice Extent, Science, 286, 1934-1937, 1999. 
Woodgate, R. A., Aagaard, K., and Weingartner, T. J.: A Year in the Physical Oceanography of the Chukchi Sea: Moored measurements from Autumn 1990-1991, Deep-Sea Res. Pt. II, 52, 3116-3149, 2005. 